\title{
Social determinants of songbird vocal activity and implications for the persistence of small populations
}

\author{
P. Laiolo ${ }^{1,2}$ \& J. L. Tella ${ }^{1}$ \\ 1 Estación Biológica de Doñana (CSIC), Avenida M. Luisa s/n, Sevilla, Spain \\ 2 Instituto Cantábrico de Biodiversidad (CSIC-UO-PA), Oviedo, Spain
}

Keywords

birdsong; conservation behaviour; conspecific attraction; habitat loss; larks.

\section{Correspondence}

Paola Laiolo, Estación Biológica de Doñana (CSIC), Avenida M. Luisa s/n, 41013 Sevilla, Spain. Tel: +34 954232340; Fax: +34 95 4621125

Email: paola@ebd.csic.es

\begin{abstract}
Conspecific attraction is an important aspect of animal behaviour and several avian studies have shown that vocalizations may be used as an inadvertent cue to locate areas of suitable habitat. By studying the metapopulation system of a territorial passerine, the Dupont's lark Chersophilus duponti, we analysed the demographic correlates of population vocal activity, and the relationships between the occurrence of immigration and the availability of social information (e.g. vocal activity, population size, density and productivity) in 22 local populations. We found that the proportion of active singing days in spring and territorial call advertisement after breeding were positively related to the number of males within local populations. In turn, the intensity of vocal activity was associated with the likelihood of receiving immigrants, better explaining immigration than other kinds of social or public information. Because of depressed signalling, small local populations could experience reduced rescuing from others, thus compromising population persistence. In such cases, habitat management alone may not be enough to overcome this behavioural constraint. Because we found that the occurrence of inter-patch movements also depended on the size of nearby local populations, understanding regional processes may be as important as controlling social and environmental factors for the maintenance of small populations.
\end{abstract}

\section{Introduction}

The integrated study of habitat selection and individual decision-making has a long history in ecological and behavioural research (MacArthur \& Pianka, 1966; Rosenzweig, 1981; Stamps, 1988). If habitats vary in profitability at different spatial and temporal scales and individual habitat choices lead to different fitness outcomes, natural selection is expected to favour the integration of complex cognitive mechanisms for assessing environmental quality (Boulinier \& Danchin, 1997). In general, it is assumed that individuals cannot always select the best habitat option because of the lack of perfect information, and thus are forced to cue on factors correlated with the intrinsic quality of a habitat (Muller et al., 1997). Among the potential cues, an individual can use its own sampling of environmental quality (Rosenzweig, 1985; Citta \& Lindberg, 2007). Alternatively, it can use social cues obtained from conspecifics or heterospecifics (Stamps, 1988; Forsman et al., 1998). Social attraction can derive either from a performance-based information ('public information' sensu Valone, 1989 and Doligez, Danchin \& Clobert, 2002, obtained from prospecting the reproductive success of others) or simply by cueing on the presence and abundance of conspecifics (Serrano et al., 2004; Sergio \& Penteriani, 2005).
Several avian studies have shown that vocalizations can function to attract new settlers either in colonial or territorial species (Alatalo, Lundberg \& Bjorkland, 1982; Kress, 1983; Ahlering, Johnson \& Faaborg, 2006). Intuitively, the use of song attraction to breeding sites seems unlikely in non-colonial species. Plenty of observational and experimental studies have in fact shown the effectiveness of song as a deterrent to the intrusion of rival males (Catchpole \& Slater, 1995). However, depending on the scale of the study, the song can become either a deterrent or an aggregative stimulus. At a very small scale, such as that of territorial aggregations, one of the primary functions of song is territorial defence (Collins, 2004). At larger spatial scales conspecific songs may be used as an inadvertent cue to locate areas of suitable habitat (Hahn \& Silverman, 2006, 2007). This implies that individuals may cue on but then compete for a specific site using vocalizations.

Sources of variation in song activity must be known for a better understanding of its potential use as a cue for breeding habitat selection. Vocal displays can show variation in relation to time, social and environmental factors. Individual vocal performance has been shown to be positively related to either density or population size in several species (Laiolo et al., 2001; Laiolo \& Tella, 2007a,b; Sexton et al., 2007). In cases of species prone to conspecific 
attraction through vocal cues, the effects of demography on vocal behaviour can have important consequences for the persistence of populations, by affecting individual decision-making during dispersion. At low population sizes vocal cues may become unavailable to guide habitat selection and the potential for Allee affects can become great (Fletcher Jr, 2007). In the context of pronounced humandriven habitat alteration, understanding the relationship between demography and habitat occupancy through social cues is critical for both basic population ecology in changing landscapes and its applied counterpart, as it could help developing sound and alternative methods for conserving species at risk. When geographically fragmented populations are declining, conventional management (such as habitat restoration) may not stop it in case of low recruitment rates due to conspecific attraction phenomena (Ward, 2005).

In this study, we analyse the demographic correlates of vocal activity and its potential use as a cue for inter-patch movements in the metapopulation system of a year-round resident passerine, the Dupont's lark Chersophilus duponti. Historical accounts indicate that Spanish populations of this species have declined and become more isolated in the last decades, with extinctions recorded for the smallest nuclei (Garza, Suarez \& Tella, 2003; Tella et al., 2005; Laiolo et al., 2008). The Dupont's lark is classified as Near Threatened in the IUCN Red List and Endangered in the Spanish Red List (Garza et al., 2003; BirdLife International, 2005). We expected vocal cues to play a role in Dupont's lark habitat selection process, given that the species actively vocalize during breeding and post-breeding, use songs and calls in competitive interactions, and the songs in mate attraction. Moreover, the availability of visual cues is limited because of its cryptic plumage and secretive behaviour (Laiolo et al., 2005; Laiolo \& Tella, 2006a, 2007a,b). Moreover, males usually sing nocturnally, a characteristic that might have evolved to attract night-dispersing females (Schlossberg \& Ward, 2004). All the above-mentioned behavioural traits have been shown to favour the use of acoustic cues in habitat selection processes (Ward \& Schlossberg, 2004; Hahn \& Silverman, 2006; Fletcher Jr, 2007).

We tested for the prediction that vocal activity can influence bird settlement decisions, and consider the effect of alternative and more direct cues that birds can use, such as population size, density and productivity (Valone, 1989; Serrano \& Tella, 2003). We first analysed the environmental, social and demographic determinants of vocal activity in 22 local populations constituting a metapopulation of Dupont's lark in NE Spain (Laiolo et al., 2008). We then tested for the relationship between immigration among patches and social or demographic cues. We expected a major role of behavioural patterns, namely vocal activity, in habitat selection of Dupont's lark individuals, in case this activity reliably indicates habitat quality (such as territory or mate availability). We also simultaneously considered other cues to explore complex habitat selection patterns, that is when individuals use more than one indicator for selecting breeding habitats (Serrano et al., 2001).

\section{Methods}

\section{Study area}

This study was carried out in a $10300 \mathrm{~km}^{2}$ area located in the Ebro Valley, north-western Spain, which holds the second largest European population of Dupont's lark (Garza et al., 2003). The Dupont's lark is a typical inhabitant of natural shrub-steppes, a habitat that has been reduced to a series of patches greatly differing in size and isolation (Tella et al., 2005; Laiolo \& Tella, 2006a,b). Twenty-two local populations constituting the bulk of Ebro Valley metapopulation were extensively surveyed from spring 2004 to spring 2007. Patch size ranged from 20 to over 2000 ha, and $36 \%$ of the steppes were smaller than 100 ha (Tella et al., 2005; Laiolo \& Tella, 2007a). Local population size ranged from 2 to 48 males per patch, and was significantly associated with patch size $\left(r=0.76, F_{1,21}=27.6\right.$, PO0.001). These small sizes are typical of this species across its current distribution in Spain (Tella et al., 2005), as a result of human-driven habitat loss and fragmentation in recent decades (Laiolo \& Tella, 2006b). Because of its cryptic and elusive behaviour, the Dupont's lark is difficult to spot but is highly vocal: males utter songs in the breeding period and territorial calls during the breeding and post-breeding periods. The former vocalization is given in a sexual context and the second is associated with territorial maintenance and self-advertisement (Laiolo \& Tella, 2005, 2006a). These vocalizations allow to accurately map the spatial distribution and number of territorial males, used as an estimate of local population size (Tella et al., 2005; Laiolo et al., 2008).

The study patches were visited from February to May and from September to October each year, to cover the periods in which the species is vocally active, that is the breeding period and the summer-autumn territory establishment time (hereafter post-breeding period). Patches were visited during the dawn and sunset chorus, and were abandoned c. $1 \mathrm{~h}$ after the last bird ended to vocalize (Laiolo \& Tella, 2006b). Male vocalizations were recorded during each visit using a digital tape recorder (Sony TC-D8 DAT, Sony, Tokyo, Japan) and a Sennheiser ME67 microphone (Sennheiser, Wedemark, Germany) and individual locations were established by means of a Global Positioning System Garmin eTrex $^{\mathbf{s}}$ Navigator (Garmin, Olathe, KS, USA). Each local population was visited 3-20 (median 10) days in February-May and 3-11 (median 4) days in SeptemberOctober, totalling 297 daily visits throughout the study period (200 during breeding, 97 during post-breeding).

\section{Environmental and social determinants of vocal activity}

Laiolo et al. (2008) analysed the determinants of song activity at the individual level, quantifying the number of vocalizations uttered per time unit (i.e. song rate). Song rate was positively associated to the number of close neighbours that were countersinging, but was not affected by any population-level parameters at a larger scale. For the 
purpose of this study, we characterized vocal activity at the population level, given that vocalizing tends to be a choral behaviour in the species. In doing so, we considered local populations as vocal units and recorded the occurrence/ absence of the different signal utterance within local populations during each visit.

The occurrence of vocal activity was not affected by sampling effort, given that the number of visits per patch was unrelated to local population size (breeding period: $r_{S}=0.31$, post-breeding period: $r_{S}=0.39, n=22$ patches, all NS). In the post-breeding period, when males typically give territorial calls only, local populations were defined either as 'vocal' (when males were calling) or 'silent' (no male was recorded calling). In the breeding period, birds tend to be more vocally active, singing and/or calling, and no cases of silent local populations were recorded (i.e. neither calling nor singing, although some small populations that were never recorded singing used to call during breeding, see Fig. 1a). Local populations were thus defined as 'singing' (a complete repertoire was recorded, both singing and calling birds), or 'calling' (i.e. no sexual signalling was uttered and just a few birds were calling).

The vocal activity of local populations was recorded as a dichotomous variable during each visit, on the basis of the occurrence or absence of the behaviour (post-breeding: $1=$ presence of calling individuals; $0=$ silent patch; $\mathrm{n}=\mathbf{9 7}$ visits; breeding: $1=$ presence of singing individuals; $0=$ absence of singing individuals; $\mathrm{n}=200$ visits). The predictors of vocal activity were analysed using generalized linear mixed models (GLIMMIX macro in SAS 9.1.3, Cary, NC, USA), using a binomial distribution with a logit link function. Local population identity was entered as a random factor. As explanatory variables, we included those environmental and social parameters that have been shown to affect vocal behaviour in passerine birds (Catchpole \& Slater, 1995). The time of the year was included to test for temporal variation and changes due to the stage of the annual cycle; we followed a consequent integer numeration scoring 1 to the 10th day of February (breeding period) and 1 to the 10th of September (post-breeding). We also tested for annual variations including the year as a further explanatory variable. Finally, variation associated with population social

(a)

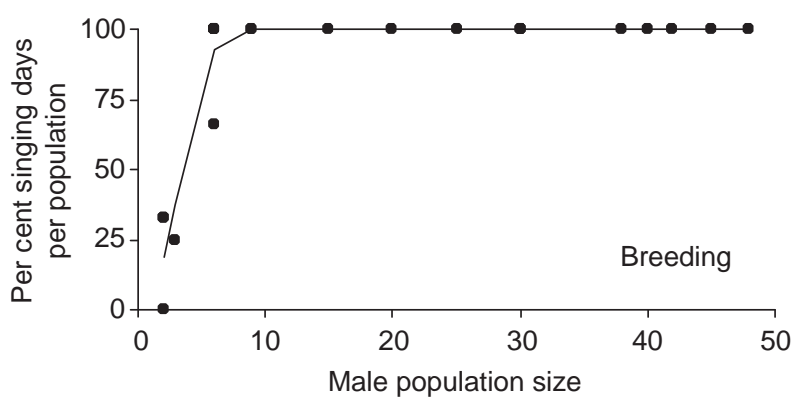

environment and competition among males was taken into account by entering male population size and mean nearest neighbour distance as a measure of male density. We first built models for testing the individual contribution of each of the explanatory variables, and then tested all the possible combinations of significant variables.

\section{Vocal activity and inter-patch movements}

The territorial calls of Dupont's lark males are individual specific, vary greatly among patches and are learned before dispersal, after a short learning phase in summer (Laiolo et al., 2007; Laiolo \& Tella, 2007a,b). Taking into account these properties, we detected inter-patch movements of males by identifying individuals uttering the territorial call types typical of another local population (see methodological details for acoustic individual recognition in Laiolo et al., 2007). 'Foreign' calls were detected either at the end of the autumn calling period (October) or at the very beginning of breeding (February). Because the territorial call is given by birds to advertise to neighbouring males their presence in a territory (Laiolo et al., 2007), we hypothesized that all immigrants were maintaining and defending a territory when we recorded their calls, and not just exploring the new patch. We consider this a reliable method to detect interpopulation male movements given that all local populations were extensively surveyed and the extent of call geographic variation was known (Laiolo \& Tella, 2006a). Notably, in species characterized by low dispersal abilities, tracking large movements by dialectal differences can be more cost efficient than using traditional capture-recapture methods (Payne, 1985; Laiolo et al., 2007). These methods usually require very large numbers of banded individuals to detect the low rates of inter-patch movements that assure gene flow (e.g. Serrano \& Tella, 2003). By using the acoustic method, we detected the immigration of nine males in seven local populations, while six populations were the sources of these immigrants. None of the 333 individuals banded with colour rings was re-sighted outside its patch, testifying the limited dispersing attitude of the species (Vogeli et al., 2008).

We tested whether immigration events occurred more frequently in the most vocally active patches, thus assuming

(b)

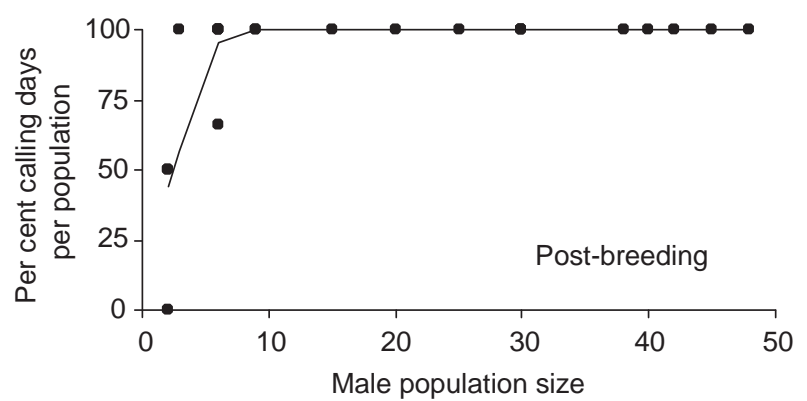

Figure 1 Relationships between Dupont's lark male population size and the percentage of singing days in spring (a) and of calling days during postbreeding (b) per subpopulation ( $n=22$ local populations). Note that raw data are plotted in (a) and therefore the effect of time of the year is not controlled for (see Table 1 for its effect). 
that birds could use acoustic cues to select breeding sites. We also considered a set of alternative hypotheses to explain settlement decisions. These were related to landscape geometry, social and public information (Clobert et al., 2001). We tested whether inter-patch movements were associated with: (1) habitat patch size (supposing that large patches had higher probabilities of being detected during dispersal); (2) patch isolation; (3) local male density (nearest neighbour distance); (4) population productivity; (5) male population size; (6) male population size for the nearest neighbour patch during each year of the study. The productivity of local populations was defined as the yearling to adult male ratio recorded during summer (Laiolo et al., 2008). In Dupont's lark's yearling, territorial calls can be separated from those of adults by the presence of quavering harmonics and relatively amorphous notes evidenced in spectrograms (details of young/adult discrimination can be found in Laiolo et al., 2008). By quantifying the proportion of yearlings among all vocalizing males in September (adults plus young), we obtained an estimate of yearling to adult male ratio per local population per year. This ratio is commonly used as a surrogate of population productivity when actual reproductive success is difficult to record (De Leo et al., 2004), as is the case in the secretive Dupont's lark. By averaging the annual productivity, we obtained a mean value per local population, following Laiolo et al. (2008).

The above spatial and social descriptors were entered in generalized linear models where local populations $(n=22)$ were described as receiving or not immigrants (binary dependent variable, 1 or 0 , respectively). Models were built through the GENMOD procedure in SAS 9.1.3, with a binomial distribution and a logit link function.

\section{Results}

\section{Environmental and social determinants of vocal activity}

The proportion of singing days per local population during breeding depended significantly upon male population size, and larger populations were more often recorded singing than smaller ones. Population singing activity also increased over the breeding period but did not show inter-annual variation or density dependence (Table 1). Larger local populations were more vocally active than smaller ones also in the post-breeding period. Year, date and nearest neighbour distance had no significant effect on the frequency of post-breeding signalling (Table 1).

We used a non-linear least square regression to better fit the percentage of singing (breeding) or calling (post-breeding) days to male population size, and to estimate the critical threshold of males at which song activity levelled off (Fig. 1). Population vocal activity was expressed as the proportion of daily visits in which birds were recorded calling (during post-breeding) or singing (during breeding) over the total number of visits to the patch. We alternatively estimated the fit of three functions expressing a non-linear rise (power, piecewise and exponential functions; see Laiolo, 2008 for a description) by means of the bias-corrected version of Akaike's information criterion $\left(\mathrm{AIC}_{\mathrm{c}}\right.$; Burnham \& Anderson, 1998). The best model fit for singing activity during breeding was provided by a piecewise function $\left(\mathrm{r}^{2}=0.91, \mathrm{~F}_{3,18}=60.8\right.$, PO0.001); the other models were

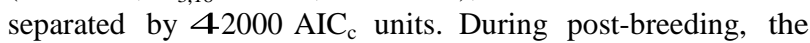
best models for call activity were a piecewise $\left(r^{2}=0.64\right.$, $\mathrm{F}_{3,18}=11.0$, PO0.001, $\mathrm{AIC}_{\mathrm{c}}=4823$ ) and an exponential model $\left(\mathrm{r}^{2}=0.64, \mathrm{~F}_{1,20}=36.7\right.$, PO0.001, $\left.\mathrm{AIC}_{\mathrm{c}}=4823\right)$; the

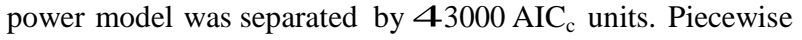
regressions showed that vocal activity increased up to a subpopulation size of $6.40 \mathrm{~T} 0.41 \mathrm{sE}$ (breeding) and 6.36 T $0.96 \mathrm{sE}$ (post-breeding) males and levelled off at larger numbers (Fig. 1)

\section{Vocal activity and inter-patch movements}

The occurrence of immigration was not significantly associated with the size of the habitat patch, local male population size, density and productivity, but depended on the size of the nearest subpopulation, the proportion of singing days in spring and that of calling days in autumn (Table 2, Fig. 2). The best fitting model included the size of nearest subpopulation and the proportion of singing days in spring

Table 1 Results of generalized linear mixed models exploring variation in (a) singing activity during breeding and (b) calling activity during postbreeding

\begin{tabular}{|c|c|c|c|c|}
\hline Hypothesized model & Estimates & SE & F-value & P-value \\
\hline \multicolumn{5}{|l|}{ (a) Breeding period } \\
\hline Year & 0.004 & 0.02 & 0.05 & 0.82 \\
\hline Time of the year & 0.021 & 0.09 & 5.78 & 0.017 \\
\hline Nearest neighbour distance & -0.006 & 0.004 & 2.51 & 0.12 \\
\hline Male population size & 0.12 & 0.03 & 21.8 & $\mathbf{0} 0.001$ \\
\hline $\begin{array}{l}\text { Time of the year +male population size } \\
\text { (b) Post-breeding period }\end{array}$ & $0.019 ; 0.11$ & $0.009 ; 0.025$ & $4.92 ; 20.63$ & $0.028 ; 00.001$ \\
\hline Year & 0.66 & 0.44 & 2.15 & 0.15 \\
\hline Time of the year & 0.013 & 0.05 & 0.08 & 0.78 \\
\hline Nearest neighbour distance & 0.004 & 0.003 & 1.86 & 0.18 \\
\hline Male population size & 0.40 & 0.15 & 7.17 & 0.0091 \\
\hline
\end{tabular}

Parameter estimates, their standard errors and F-statistics are also shown. 
Table 2 Results of generalized linear models exploring variation in the occurrence of immigration events

\begin{tabular}{|c|c|c|c|c|c|c|c|c|}
\hline Hypothesized model & Estimates & SE & $w^{2}$ & P-value & $\begin{array}{l}\text { Explained } \\
\text { deviance } \\
(\%)\end{array}$ & $\mathrm{AlC}_{\mathrm{c}}$ & DAIC $_{c}$ & $\begin{array}{l}\text { Akaike } \\
\text { weight }\end{array}$ \\
\hline Patch size & -0.0005 & 0.00 & 0.29 & 0.59 & 1.05 & 29.85 & 11.40 & 0.002 \\
\hline Distance to the nearest patch & 0.099 & 0.11 & 0.95 & 0.33 & 3.45 & 29.19 & 10.74 & 0.003 \\
\hline Productivity & 0.061 & 0.004 & 2.47 & 0.12 & 8.95 & 27.17 & 8.72 & 0.007 \\
\hline Nearest neighbour distance & 0.040 & 0.030 & 1.97 & 0.16 & 7.19 & 28.07 & 9.62 & 0.004 \\
\hline Male population size & 0.0048 & 0.040 & 2.07 & 0.15 & 7.52 & 28.17 & 9.72 & 0.004 \\
\hline Male population size of the nearest population & 0.076 & 0.037 & 5.09 & 0.025 & 18.50 & 25.05 & 6.60 & 0.020 \\
\hline Per cent of singing days during breeding & 0.046 & 0.020 & 5.10 & 0.024 & 18.53 & 25.05 & 6.60 & 0.020 \\
\hline Per cent of calling days during post-breeding & 0.066 & 0.042 & 5.53 & 0.019 & 20.13 & 24.61 & 6.16 & 0.025 \\
\hline $\begin{array}{l}\text { Male population size of the nearest } \\
\text { population+per cent of calling days during } \\
\text { post-breeding + per cent of singing days } \\
\text { during breeding }\end{array}$ & $\begin{array}{l}0.14 ; 0.069 \\
0.041\end{array}$ & $\begin{array}{l}0.072 ; 0.081 ; \\
0.074\end{array}$ & $\begin{array}{l}5.09 ; 8.31 ; \\
0.24\end{array}$ & $\begin{array}{l}0.024 ; 0.0039 ; \\
0.062\end{array}$ & 49.58 & 20.21 & 1.76 & 0.224 \\
\hline $\begin{array}{l}\text { Male population size of the nearest } \\
\text { population+per cent of singing days during } \\
\text { breeding }\end{array}$ & $0.16 ; 0.11$ & $0.077 ; 0.064$ & $8.30 ; 8.31$ & $0.0040 ; 0.0039$ & 48.69 & 18.45 & 0.00 & 0.540 \\
\hline $\begin{array}{l}\text { Per cent of singing days during breeding }+ \text { per } \\
\text { cent of calling days during post-breeding }\end{array}$ & $0.021 ; 0.049$ & $0.027 ; 0.046$ & $5.10 ; 1.26$ & $0.020 ; 0.026$ & 23.11 & 25.49 & 7.04 & 0.016 \\
\hline $\begin{array}{l}\text { Male population size of the nearest } \\
\text { population+ per cent of calling days during post- } \\
\text { breeding }\end{array}$ & $0.097 ; 0.077$ & $0.045 ; 0.0000$ & $5.09 ; 5.53$ & $0.024 ; 0.019$ & 38.63 & 21.21 & 2.76 & 0.136 \\
\hline
\end{tabular}

The best models are those separated by less than two $\mathrm{AIC}_{\mathrm{c}}$ points $\left(\mathrm{DAIC}_{\mathrm{C}} \mathrm{O} 2\right)$ from the most probable model and those showing the greatest Akaike weights (given in bold). Parameter estimates, P-values of each predictor in the model and the overall explained deviance are also shown.
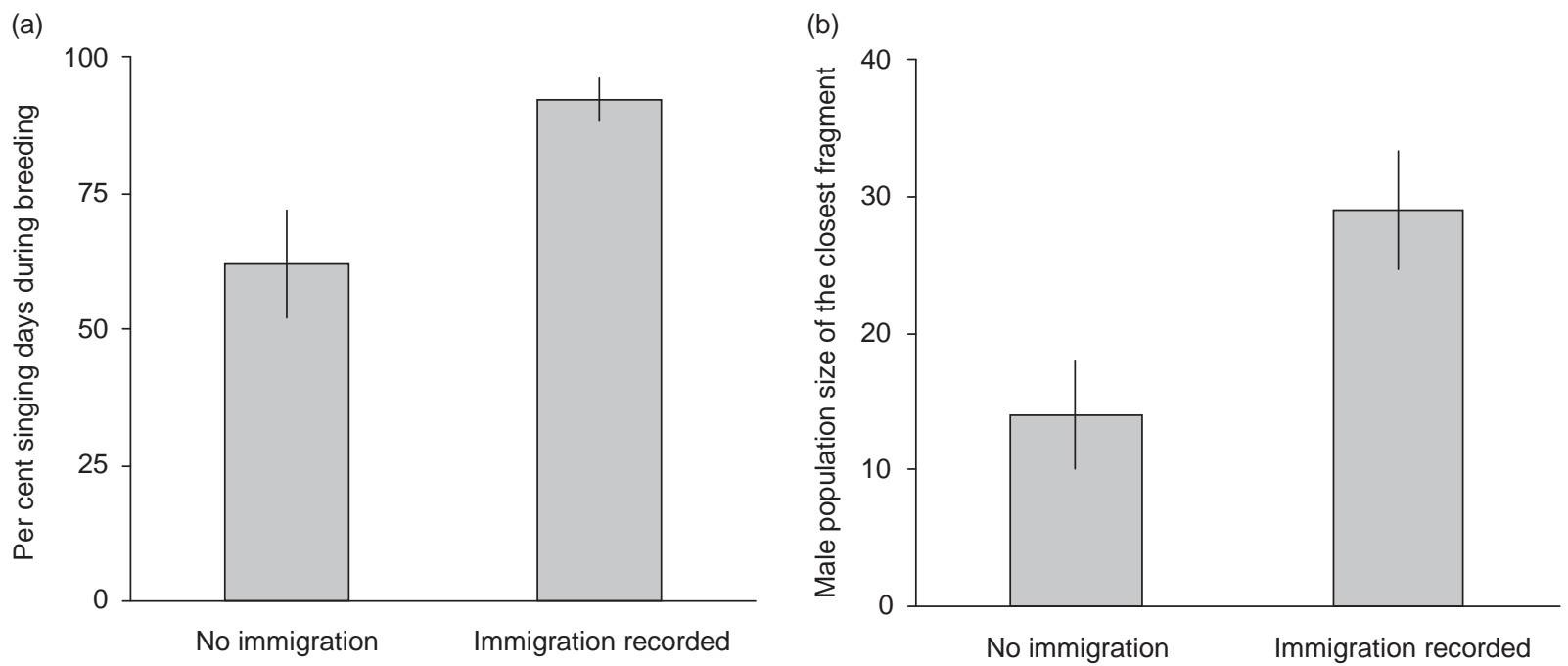

Figure 2 Patches receiving male immigrants tended to be more active vocally (a) and closer to larger male subpopulations (b) than those where immigration was not recorded (means T SE are shown; $n=22$ local populations).

$\left(\mathrm{AIC}_{\mathrm{c}}=18.45\right)$, and their combination with the proportion of calling days in autumn was almost equally probable $\left(\mathrm{AIC}_{\mathrm{c}}=20.21\right.$ ) (Table 2). Therefore, populations receiving immigrations were not larger or denser than the others (Mann-Whitney U-test: $U=29.5$ and 39.5, $Z=-1.6$ and $0.9, \mathrm{n}=22, \mathrm{P}=0.11$ and 0.37 ), but were indeed more vocally active (Fig. 2). The greatest number of colonization events (one third) was in fact recorded in a population inhabited by nine males only. Conversely, significant differ- ences in size were recorded between the sources populations and those that did not provide emigrants (33 T $3.8 \mathrm{SE}$ vs. 13 T 3.6 males; Mann-Whitney U-test: $U=13, \mathrm{Z}=-2.6$, $\mathrm{n}=22, \mathrm{P}=0.007$ ).

\section{Discussion}

Conspecific attraction, a conspicuous feature in colonial or semi-colonial species, has been recently demonstrated in 
several territorial species as well, with many of the best examples coming from birds. Literature on the subject mostly centred on the identification of the cues that attract birds to a habitat (Serrano et al., 2001; Doligez et al., 2002; Sergio \& Penteriani, 2005), but poor attention was paid to the determinants of cue output, in spite of the important implications for bird space use and, therefore, for conservation and restoration. By studying the metapopulation system of a territorial passerine, we found that the likelihood of receiving immigrants was positively associated with the intensity of vocal activity, which was a better descriptor of inter-patch movements than other kinds of social or public information, such as local population density, size or reproductive success. In turn, the acoustic activity within local populations was positively related to male numbers, and dropped in very small ones. Because of this depressed signalling, small subpopulations could experience reduced rescuing from others, with potentially negative implications for the persistence of both local populations and the metapopulation as a whole.

Social factors may determine the observed association between Dupont's lark vocal activity and population size. Laiolo \& Tella (2007a,b) found greater territorial turnover and within-patch movements in larger than in smaller populations. Larger patches also host higher proportions of young individuals than do smaller ones (Laiolo et al., 2008). Therefore, the intensity of acoustic territorial defence might be greater in larger populations, because long established territorial males would be more acoustically active towards strangers than familiar owners that represent a lower threat. In general terms, the hypothesized decrease in male aggressiveness in small nuclei might be a side effect of this 'dear-enemy' recognition, that is when individuals tend to be more aggressive towards strangers than familiar neighbours (Fisher, 1954). This phenomenon is known to occur in many vertebrate and invertebrate species (Jaeger, 1981; Langen, Tripet \& Nonacs, 2000; Lopez \& Martin, 2002; Wich \& Sterck, 2007) and has been demonstrated in a closely related lark species, the skylark Alauda arvensis (Briefer et al., 2008).

We found that the relationship between acoustic signalling and male numbers was not linear, and acoustic activities stabilized when subpopulations hosted more than six males (Fig. 1). If we consider the male-biased adult sex ratio in the species (4:1, Vogeli et al., 2007), it seems likely that populations below the above threshold were inhabited by few females, a factor that can condition male settlement decisions. This demographical bias may have further depressed sexual signalling in small fragments, as demonstrated by the absence of singing individuals in the smallest populations, where only territorial advertising was recorded.

Among the determinants of singing activity, it is worth mentioning the effects of the date, with increasing occurrence of songs as the breeding season progressed. Seasonal and dial patterns of singing activity of male birds have been reported by several studies, which highlighted the role of female fertility or territorial defence in determining temporal variation (Mace, 1987; Kunc, Amrhein \& Naguib, 2005).
The Dupont's lark has a long breeding season characterized by high nest-failure rates that force birds to multiple breeding attempts (Cramp, 1988). From February to June, conditions for reproduction progressively improve in association with better weather conditions, and this would drive the observed increase of song activities towards the end of the season.

So far, the influence of demographic parameters on population and individual song rates has been described in behavioural ecology studies (Penteriani, 2003), but is also known by researchers involved in species monitoring, as small populations can be harder to detect through song (Tryjanowski \& Sparks, 2001). Therefore, our study is not new in demonstrating this association. Our results, however, go further by suggesting a novel link between individual behavioural processes, population properties (size, density, adult sex ratios) and settlement decisions, driven by conspecific attraction through vocal signalling. Indirect evidence of conspecific attraction in this species is also provided by two observations: (1) apparently suitable habitat patches can remain unoccupied and (2) individuals are often patchily distributed in territorial aggregations even at small scales, that is within local populations (Tella et al., 2005; Laiolo \& Tella, 2005). Patchy distribution patterns are often interpreted in terms of conspecific attraction in avian species (Serrano \& Tella, 2003). Being this study correlative, we cannot exclude alternative explanations to territorial clustering, such as patchy food distribution or male 'hidden leks' (territorial aggregation maintained by extrapair copulation behaviour; Wagner, 1998). If the rate of territorial advertisement relates to the quality and quantity of resources (food or female fertility), a spurious relationship between acoustic activity and immigration can result. However, it is precisely under these conditions that the use of inadvertent information might have evolved to assess resource levels (Lewis, 1986). In our study, dispersing Dupont's lark males may avoid selecting suboptimal habitats by using acoustic cues, which might reduce search and settlement costs, and the risks of Allee effects (Greene \& Stamps, 2001). In particular, the utterance of territorial calls may indicate the presence of occupied territories, making an area attractive for dispersing birds (Laiolo et al., 2007), whereas the song could likely advertise mate availability in a species in which females are a limited resource (Vogeli et al., 2007).

As we expected, conspecific information other than acoustic one (male number, density and productivity) was less effective in explaining variation in immigration patterns, although it may correlate with habitat quality more directly than vocalizations. Acoustic information may be easier to gather than visual ones in our study model, due to the bird secretive behaviour and nesting location varying across the breeding season. Song can therefore be viewed as the most probable candidate cue in this species.

In conclusion, this study shows that population size is important in explaining both immigration and emigration patterns. Large fragments are potential sources of dispersing males (this study), and tend to be more productive than 
smaller ones (Laiolo et al., 2008). The long-term persistence of small populations might therefore depend on the preservation of nearby large fragments if immigration can buffer from extinction risk, thus supporting the idea of regional population regulation in a metapopulation systems. From a methodological point of view, this study shows that the analysis of dialectal variation can be used as a tool to highlight bird movements in species with limited dispersal abilities, which would require large-scale monitoring programmes to be detected.

\section{Conservation implications}

Understanding behavioural patterns may be as important for animal species conservation as understanding their environment. Conspecific attraction has been identified as a potential mechanism to explain the widespread pattern of animal sensitivity to fragmentation, since it influences distributions by generating patch size effects (Fletcher $\mathrm{Jr}$, 2006). In case a species uses social cues in habitat selection, focusing on traditional conservation practices such as restoring habitats, controlling environment degradation and predators may not be sufficient for its conservation (Reed, 1999; Ward \& Schlossberg, 2004). In this context, conspecific attraction studies suggest new and promising management techniques, such as the use of playbacks to elicit colonization and rescue effects in high-quality unoccupied habitats (Kress, 1983; Ward \& Schlossberg, 2004).

Although our correlative results should be interpreted cautiously in the absence of experimental tests, this study sets useful ideas for the management of declining passerine populations, such as manipulating cues to attract individuals in 'acoustically depressed' populations, provided that the habitat is suitable. Of course, as Ahlering \& Faarborg (2006) pointed out, manipulations should not attract birds into sink habitats where they have little chance of breeding successfully. More research is therefore needed to understand the fitness outcome at different density and environmental conditions, and the proximate reasons why individuals use conspecific information. All in all, this study suggests that taking into account the population consequences of bird behaviour and controlling both local (within patches) and regional (among patches) processes may be important for the conservation of imperilled species in fragmented landscapes.

\section{Acknowledgements}

This study was supported by a Marie Curie Intra-European Fellowship within the 6th European Framework Program (P.L.), by a Ramon y Cajal contract of the Spanish Ministry of Education and Science (P.L.), and by an Excellence Project of the Junta de Andalucia (J.L.T.). We are grateful to two anonymous referees for providing helpful comments to an earlier version of the paper, and to F. Sergio for fruitful discussion of the results.

\section{References}

Ahlering, M.A. \& Faarborg, J. (2006). Avian habitat management meets conspecific attraction: if you built it, will they come? Auk 123, 201-312.

Ahlering, M.A., Johnson, D.H. \& Faaborg, J. (2006). Conspecific attraction in a grassland bird, the Baird's Sparrow. J. Field Ornithol. 77, 365-371.

Alatalo, R.V., Lundberg, A. \& Bjorkland, M. (1982). Can the song of male birds attract other males? An experiment with the pied flycatcher Ficedula hypoleuca. Bird Behav. 4, 42-45.

BirdLife International (2005). Chersophilus duponti. INCN 2007. 2007 IUCN Red List of Threatened Species. http:// www.iucnredlist.org

Boulinier, T. \& Danchin, E. (1997). The use of conspecic reproductive success for breeding patch selection in territorial migratory species. Evol. Ecol. 11, 505-517.

Briefer, E., Aubin, T., Lehongre, K. \& Rybak, F. (2008). How to identify dear enemies: the group signature in the complex song of the skylark Alauda arvensis. J. Exp. Biol. 211, 317-326.

Burnham, K.P. \& Anderson, D.R. (1998). Model selection and inference: a practical information-theoretic approach. New York, USA: Springer-Verlag.

Catchpole, C.K. \& Slater, P.J.B. (1995). Bird song: biological themes and variations. Cambridge: Cambridge University Press.

Citta, J.J. \& Lindberg, M.S. (2007). Nest-site selection of passerines: effects of geographic scale and public and personal information. Ecology 88, 2034-2046.

Clobert, J., Danchin, E., Dhondt, A.A. \& Nichols, J.D.

(2001). Dispersal. New York: Oxford University Press. Collins, S. (2004). Vocal fighting and flirting: the functions of birdsong. In Nature's music: the science of birdsong: 39-79. Marler, P \& Slabbekoorn, H (Eds). San Diego, CA: Elsevier Academic Press.

Cramp, S. (1988). The Birds of the Western Palearctic. Vol. 5. New York: Oxford University Press.

De Leo, G.A., Focardi, S., Gatto, M. \& Cattadori, I.M. (2004). The decline of the grey partridge in Europe: comparing demographies in traditional and modern agricultural landscapes. Ecol. Model. 177, 313-335.

Doligez, B., Danchin, E. \& Clobert, J. (2002). Public information and breeding habitat selection in a wild bird population. Science 297, 1168-1170.

Fisher, J. (1954). Evolution and bird sociality. In Evolution as a process: 71-83. Huxley, J., Hardy, A.C. \& Ford, E.B. (Eds). London: Allen \& Unwin.

Fletcher, R.J., Jr. (2006). Emergent properties of conspecific attraction in fragmented landscapes. Am. Nat. 168, 207-219.

Fletcher, R.J., Jr. (2007). Species interactions and population density mediate the use of social cues for habitat selection. J. Anim. Ecol. 76, 598-606.

Forsman, J.T., Monkkonen, M., Helle, P. \& Inkeroinen, J. (1998). Heterospecific attraction and food resources in 
migrants' breeding patch selection in northern boreal forests. Oecologia 115, 278-286.

Garza, V., Suarez, F. \& Tella, J.L. (2003). Alondra de Dupont Chersophilus duponti. In Atlas de las Aves reproductoras de España: 364-365. Mart1, R. \& del Moral, J.C. (Eds). Madrid, Spain: Direccion General de Conservacion de la Naturaleza-SEO/BirdLife.

Greene, C.M. \& Stamps, J.A. (2001). Habitat selection at low population densities. Ecology 82, 2091-2100.

Hahn, B.A. \& Silverman, E.D. (2006). Social cues facilitate habitat selection: american redstarts establish breeding territories in response to song. Biol. Lett. 2, 337-340.

Hahn, B.A. \& Silverman, E.D. (2007). Managing breeding forest songbirds with conspecific song playbacks. Anim. Conserv. 10, 436-441.

Jaeger, R. (1981). Dear enemy recognition and the costs of aggression between salamanders. Am. Nat. 117, 962-974.

Kress, S.W. (1983). The use of decoys, sound recordings and gull control for re-establishing a tern colony in Maine. Colonial Waterbirds 6, 185-196.

Kunc, H.P., Amrhein, V. \& Naguib, M. (2005). Seasonal changes of dawn song characteristics in nightingales and their relation to breeding cycle and mating status. Anim. Behav. 70, 1265-1271.

Laiolo, P. (2008). Characterizing the spatial structure of songbird cultures. Ecol. Appl., in press.

Laiolo, P., Rolando, A., Delestrade, A. \& De Sanctis, A. (2001). Geographic diversification in the call repertoire of the genus Pyrrhocorax (Aves, Corvidae). Can. J. Zool. 79, 1568-1576.

Laiolo, P. \& Tella, J.L. (2005). Habitat fragmentation affects culture transmission: patterns of song matching in Dupont's lark. J. Appl. Ecol. 42, 1183-1193.

Laiolo, P. \& Tella, J.L. (2006a). Landscape bioacoustics allows detection of the effects of habitat patchiness on population structure. Ecology 87, 1203-1214.

Laiolo, P. \& Tella, J.L. (2006b). Fate of unproductive and unattractive habitats: recent changes in Iberian steppes and their effects on endangered avifauna. Environ. Conserv. 33, 223-232.

Laiolo, P. \& Tella, J.L. (2007a). Erosion of animal cultures in fragmented landscapes. Front. Ecol. Environ. 5, 68-72.

Laiolo, P. \& Tella, J.L. (2007b). Vocal diversity patterns Reply. Front. Ecol. Environ. 8, 406-407.

Laiolo, P., Vogeli, M., Serrano, D. \& Tella, J.L. (2005). Two new calls from the Dupont's Lark Chersophilus duponti and imitations by other Alaudids: ecological and monitoring implications. Ardeola 52, 167-172.

Laiolo, P., Vogeli, M., Serrano, D. \& Tella, J.L. (2007). Testing acoustic versus physical marking: two complementary methods for individual-based monitoring of elusive species. J. Avian Biol. 38, 672-681.

Laiolo, P., Vogeli, M., Serrano, D. \& Tella, J.L. (2008). Song diversity predicts the viability of fragmented bird populations. PLoS-ONE 3, e1822.
Langen, T.A., Tripet, F. \& Nonacs, P. (2000). The red and the black: habituation and the dear-enemy phenomenon in two desert Pheidole ants. Behav. Ecol. Sociobiol. 48, 285-292.

Lewis, R.A. (1986). Aggressiveness, incidence of singing and territory quality of male blue grouse. Can. J. Zool. 64, 1426-1429.

Lopez, P. \& Martin, J. (2002). Chemical rival recognition decreases aggression levels in male Iberian wall lizards, Podarcis hispanica. Behav. Ecol. Scociobiol. 51, 461-465.

MacArthur, R.H. \& Pianka, E.R. (1966). On optimal use of a patchy environment. Am. Nat. 100, 603-609.

Mace, R. (1987). The dawn chorus in the great tit Parus major is directly related to female fertility. Nature 330 , 745-746.

Muller, K.L., Stamps, J.A., Krishnan, V.V. \& Willits, N.H. (1997). The Effects of Conspecific Attraction and Habitat Selection in Territorial Birds (Troglodytes aedon). Am. Nat. 150, 650-661.

Payne, R.B. (1985). Song populations and dispersal in Steelblue and Purple Widowfinches. Ostrich 56, 135-146.

Penteriani, V. (2003). Breeding density affects the honesty of bird vocal displays as possible indicators of male/territory quality. Ibis 145, E127-E135.

Reed, J.M. (1999). The role of behaviour in recent avian extinctions and endangerments. Conserv. Biol. 13, 232-241.

Rosenzweig, M.L. (1981). A theory of habitat selection. Ecology 62, 327-335.

Rosenzweig, M.L. (1985). Some theoretical aspects of habitat selection. In Habitat selection in birds: 517-540. Cody, M.L. (Ed.). Orlando: Academic Press.

Schlossberg, S. \& Ward, M.P. (2004). Using conspecific attraction to conserve endangered species. Endangered Species Update 21, 132.

Sergio, F. \& Penteriani, V. (2005). Public information and territory establishment in a loosely colonial raptor. Ecology 86, 340-346.

Serrano, D., Forero, M.G., Donazar, J.A. \& Tella J, L. (2004). The role of dispersal and social attraction on colony dynamics of lesser kestrels. Ecology 85, 3438-3447.

Serrano, D. \& Tella, J.L. (2003). Dispersal within a spatially structured population of lesser kestrels: the role of spatial isolation and conspecific attraction. J. Anim. Ecol. 72, 400-410.

Serrano, D., Tella, J.L., Forero, M. \& Donazar, J.A. (2001). Factors affecting breeding dispersal in the facultatively colonial lesser kestrel: individual experience vs. conspecific cues. J. Anim. Ecol. 70, 568-578.

Sexton, K., Murphy, M.T., Redmond, L.J. \& Dolan, A.C. (2007). Dawn song of eastern kingbirds: intrapopulation variability and sociobiological correlates. Behaviour 144, 1273-1295.

Stamps, J.A. (1988). Conspecific attraction and aggregation in territorial species. Am. Nat. 131, 329-347.

Tella, J.L., Vogeli, M., Serrano, D. \& Carrete, M. (2005). Current status of the endangered Dupont's lark in Spain: 
overestimation, decline, and extinction of local populations. Oryx 39, 90-94.

Tryjanowski, P. \& Sparks, T.H. (2001). Is the detection of the first arrival date of migrating birds influenced by population size? A case study of the red-backed shrike Lanius collurio. Int. J. Biometeorol. 45, 217-219.

Valone, T.J. (1989). Group foraging, public information, and patch estimation. Oikos 56, 357-363.

Vogeli, M., Laiolo, P., Serrano, D. \& Tella, J.L. (2008). Who are we sampling? Apparent survival differs between methods in a secretive species. Oikos, in press.

Vogeli, M., Serrano, D., Tella, J.L., Mendez, M. \& Godoy, J.A. (2007). Sex determination Dupont's lark Chersophilus duponti using molecular sexing and discriminant functions. Ardeola 54, 69-79.
Wagner, R.H. (1998). Hidden leks: sexual selection and the clustering of avian territories. In Avian reproductive tactics: female and male perspectives: 123-145. Parker, P.G. \& Burley, N.T. (Eds). Washington, DC: American Ornithologists' Union.

Ward, M.P. (2005). The role of immigration in the decline of an isolated migratory bird population. Conserv. Biol. 19, 1528-1536.

Ward, M.P. \& Schlossberg, S. (2004). Conspecific attraction and the conservation of territorial songbirds. Conserv. Biol. 18, 519-525.

Wich, S.A. \& Sterck, E.H.M. (2007). Familiarity and threat of opponents determine variation in Thomas langur (Presbytis thomasi) male behaviour during between-group encounters. Behaviour 144, 1583-1598. 